\title{
DESCRIPTION OF UNDERSTORY DEVELOPMENT IN A TREE PLANTATION WITH A NEW METHOD OF DATA STRUCTURING
}

\author{
Stephen KISTLER, Andrew G. STEPHENSON \& William S. BENNINGHOFF** \\ Department of Botany, Division of Biological Sciences, The University of Michigan, Ann Arbor, Michigan 48109, USA
}

Keywords:

Clustering, Data-processing, Michigan, Numerical method, Phytosociology, Stratum, Understory, Development

\section{Introduction}

One of the oldest forest plantations in North America provided an opportunity to examine the influence of different canopies on the floristic and structural development of the understory vegetation. The Saginaw Forest comprises approximately 40.5 hectares of experimental tree plantations five $\mathrm{km}$ west of Ann Arbor (42.16 $30^{\prime \prime}$ N. Lat., $83^{\circ} 48^{\prime}$ W. Long.) on moderate morainal topography from 276 to $306 \mathrm{~m}$ above sea level. The site, abandoned as farm land in the 1890 's, was planted with selected native and exotic tree species beginning in 1901 (School of Natural Resources, University of Michigan, 1966). In addition to 54 tree plantations, ranging in area from 0.05 to 1.64 ha, the property includes Third Sister Lake (4.45 ha), natural swamp ( $2.83 \mathrm{ha})$, and other small areas unsuitable for plantations (Fig. 1). Except for the natural Quercus-Carya stand outside the north boundary, nonforested land surrounds, the Saginaw Forest. The canopy trees were planted as seeds or seedlings between 1904 and 1938, and records of forestry treatments have been maintained (School of Natural Resources, University of Michigan, 1966). The conifer plantations are showing signs of overmaturity, whereas the hardwood stands are maintaining relatively good growth and freedom from disease.

\footnotetext{
* Nomenclature follows Gleason \& Cronquist (1963).

** We wish to thank James Bruce, Thomas Friedlander, Lawrence Mellichamp and Wayt Thomas for their help in plant identifications and to Deborah Rabinowitz in critiquing an earlier version of the manuscript. We are especially grateful to George Estabrook who helped in many phases of the data analysis, and Neal Oden, who wrote the computer program.
}

This study describes 30 forest stands, and compares the stand data to determine the extent of influence from the canopy on the understory synusiae. In the course of the study, a new approach was devised for analysis of relevé matrices; this method gives promise of wider applicability for analysis of stratified vegetation.

\section{Methods}

During May and June, 1974, thirty plantations were sampled by the relevé method (Braun-Blanquet 1964, Benninghoff 1966). 25 plantations and one natural Quercus-Carya stand adjacent to the north end of the Forest property (rel. 4) were sampled by $20 \times 20 \mathrm{~m}$ plots. In three plantations (rel. 9, 17, and 23) $15 \times 15 \mathrm{~m}$ plots were used. In one plantation (rel. 26) a $10 \times 10 \mathrm{~m}$ plot was used to avoid edge effect, footpath weed communities, and openings still adjusting to canopy thinnings. At each plot cover/abundance estimates of all vascular species were recorded, and the height and cover of each stratum was estimated. The cover/abundance values (adapted from Braun-Blanquet 1932,1964) follow the notations:

Braun-Blanquet $\mathrm{r}+12345$ notation

$\begin{array}{lllllllll}\text { Notation } & 1 & 2 & 3 & 4 & 5 & 6 & 7\end{array}$ used here

The 30 relevés comprise 132 vascular species in four stratal societies (Table 1). The four strata recognized are as follows :

1 All foliage cover above $3 \mathrm{~m}$

2 Cover from 1.5 to $3 \mathrm{~m}$

3 Cover from 0.5 to $1.5 \mathrm{~m}$

4 Cover at levels below $0.5 \mathrm{~m}$ 


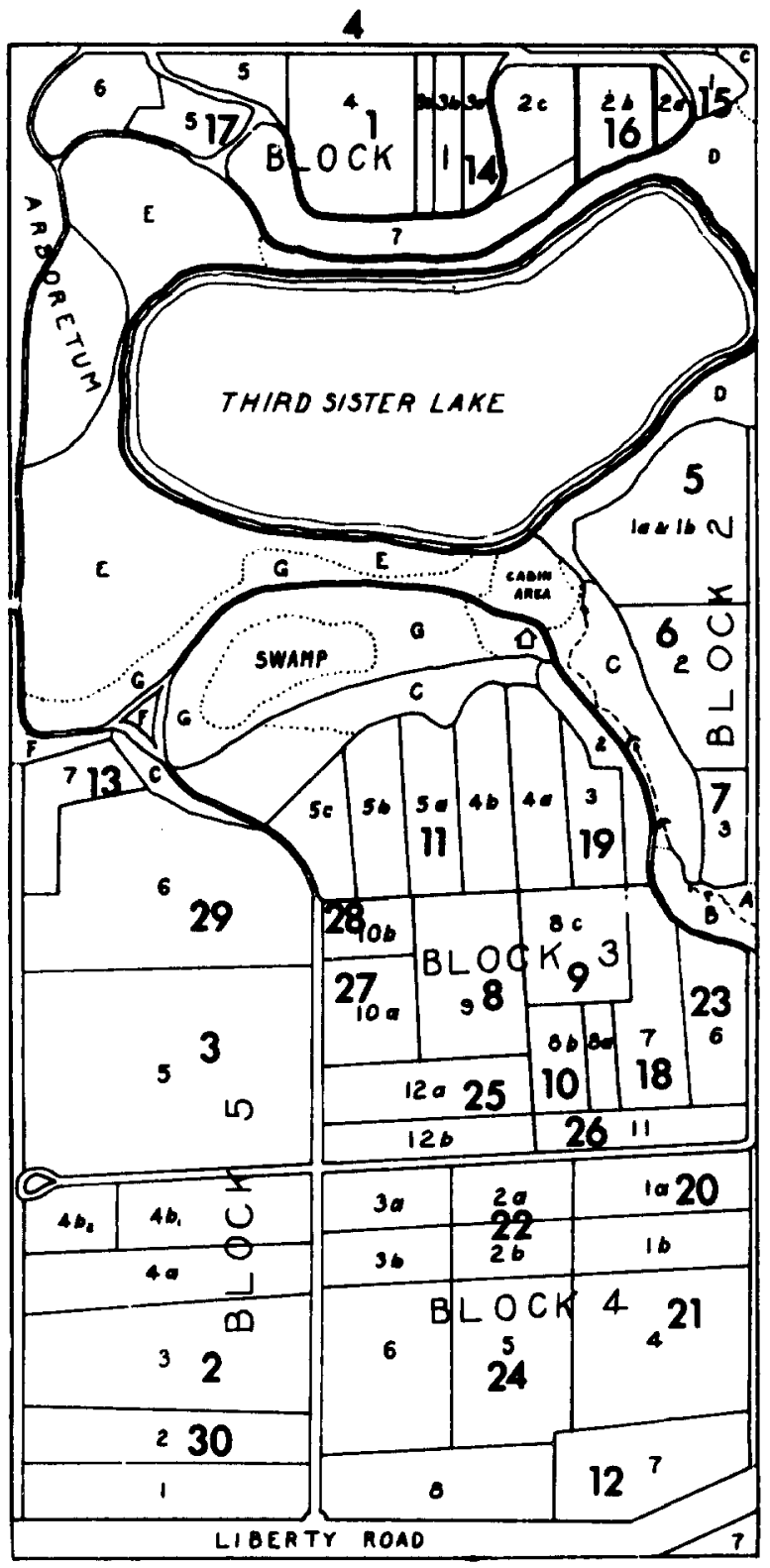

PLANTATIONS

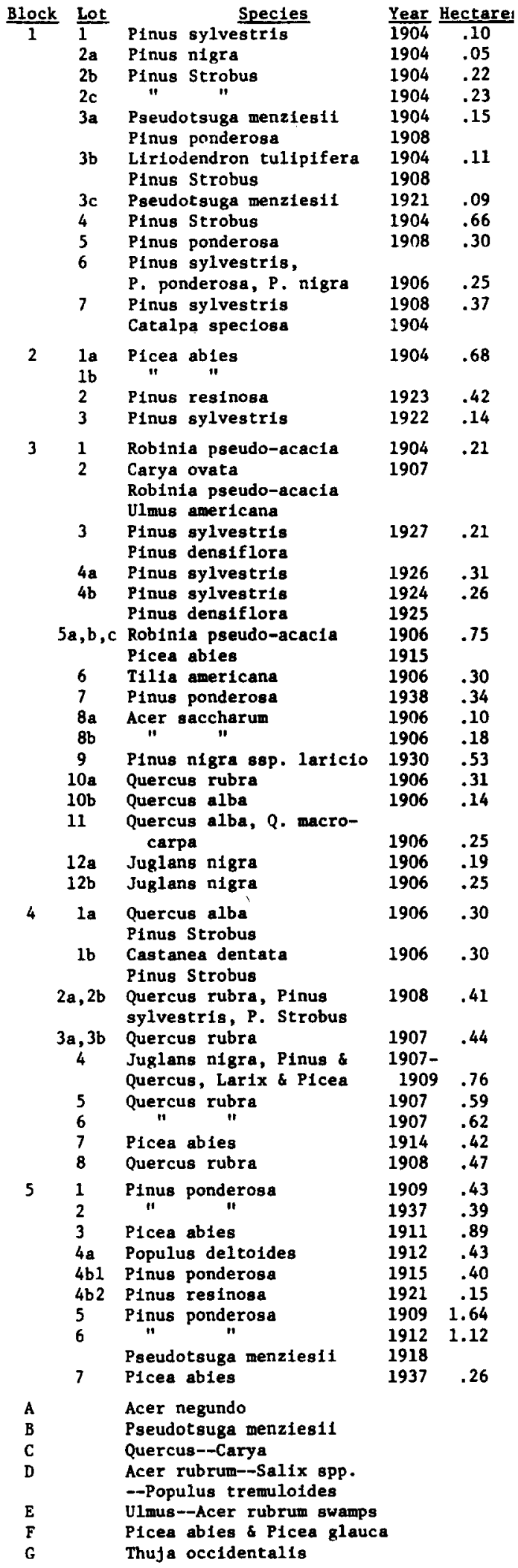

Figure 1. Map of the Saginaw Forest and list of plantations and other vegetation units. 


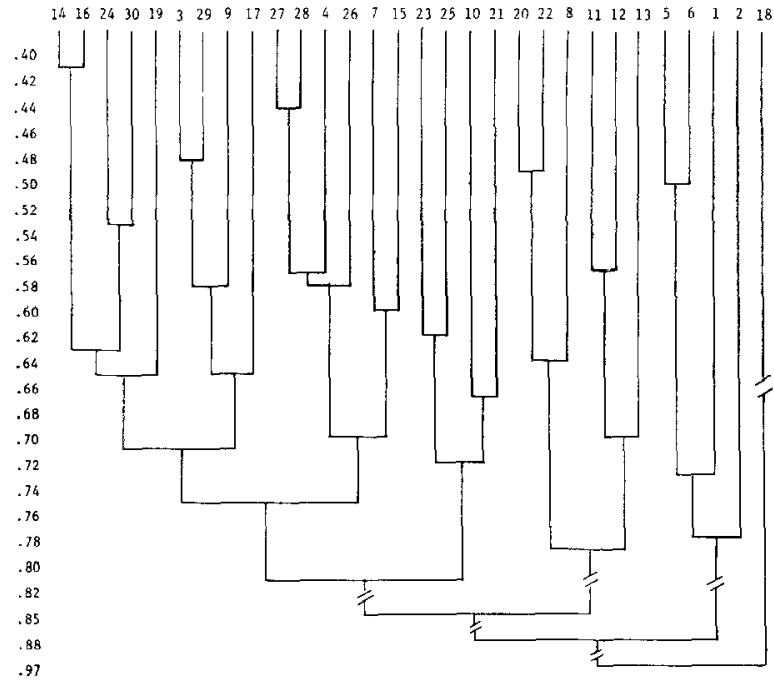

Fig. 2. Dendrogram from results of $D I F 1$, run 1 , in which presence/absence data from all four strata were employed. Compare with Table 2a.

Relevé 18 , a Pinus ponderosa plantation heavily invaded by Acer saccharum had the fewest species, 13. Rel. 4, the old-growth (probably original but selectively logged) Quercus-Carya forest, and rel. 13, a Picea abies plantation, tied for the greatest number of species, 42 .

Analysis by differential tables was laborious and unproductive. Consequently, a new numerical method employing computer techniques was developed and used

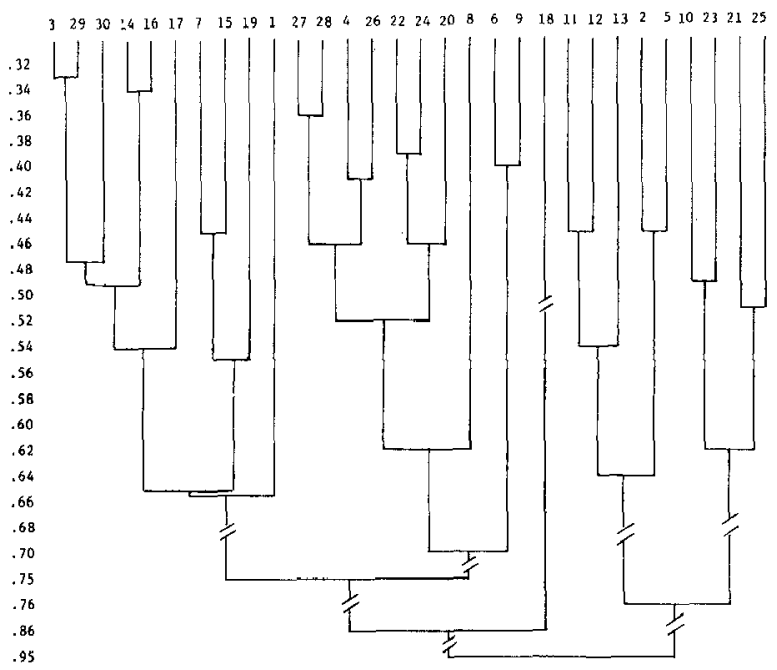

Fig. 4. Dendrogram from results of $D I F 2$, run 1 , in which cover/ abundance data for species in all four strata were employed. Compare with Table $3 \mathrm{a}$.

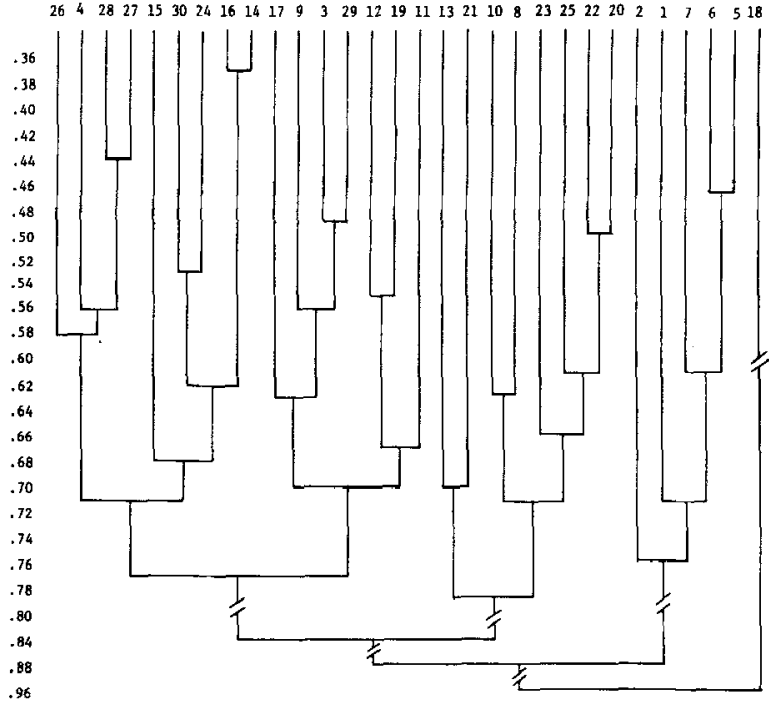

Fig. 3. Dendrogram from results of $D I F$ 1, run 2, in which presence/absence data from only the three lower strata were employed. Compare with Table $2 b$.

for detecting patterns of associated species within the table of 30 releves. The method is composed of two algorithms. The first involves the calculation of a difference value between each pair of relevés. In the second algorithm, the relevés are grouped.

Two difference measures are used in the first algorithm. Difference measure $1(D I F 1)$ is defined as the number of species unique to each relevé divided by the number of

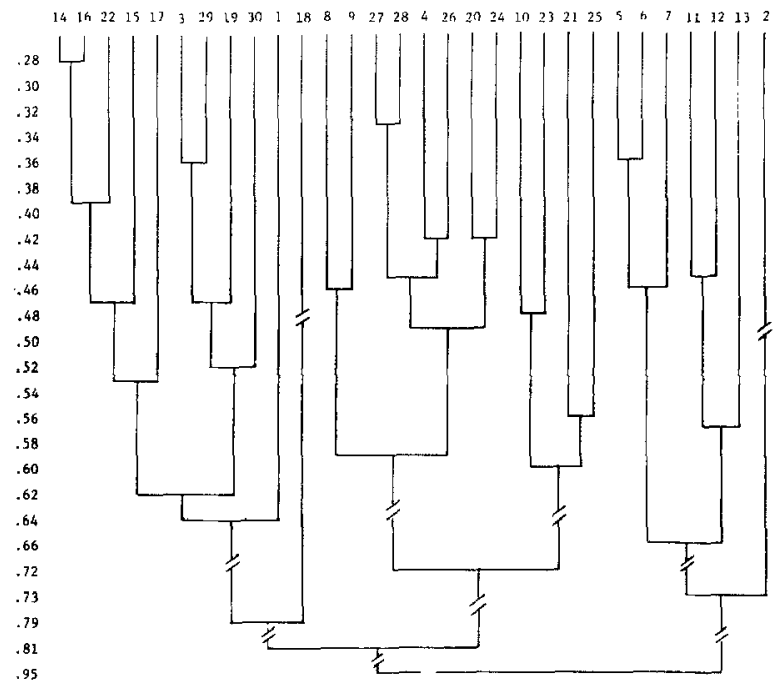

Fig. 5. Dendrogram from results of $D I F 2$, run 2, in which cover/ abundance data for species in only the thiee lower strata were employed. Compare with Table $3 \mathrm{~b}$. 
Table 2. Arrangement of relevés into groups and sub-groups relating to tree canopy cover types by DIF 1 , based on presence/ absence data for species. $2 a$ : the arrangement achieved by RUN 1 using data from all four strata. $2 b$ : the arrangement achieved by RUN 2 using data only from the lower three strata.

$$
\text { Table 2a }
$$

DIF 14 STRATA FARTHEST NEIGHBOR

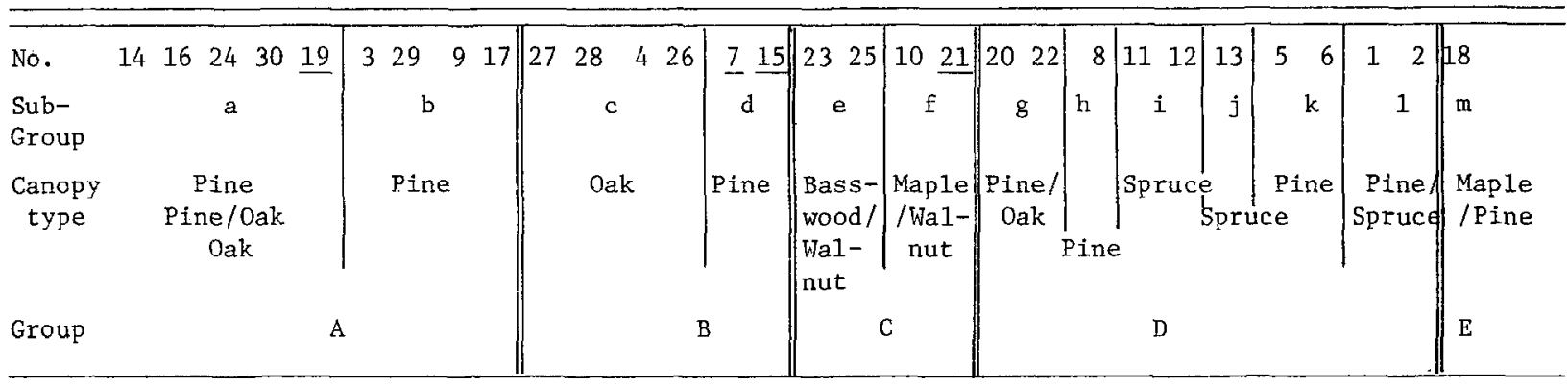

Table $2 b$

DIF 13 STRATA FARTHEST NETGHBOR

\begin{tabular}{|c|c|c|c|c|c|c|c|c|c|c|c|}
\hline $\begin{array}{l}\text { No. } \\
\text { Sub- } \\
\text { Group }\end{array}$ & 26 & $\begin{array}{ccc}4 & 28 & 27 \\
c & \end{array}$ & $\begin{array}{ccccc}15 & 30 & 24 & 16 & 14 \\
a^{\prime} & & & \end{array}$ & $\mid \begin{array}{cccc}17 & 9 & 3 & 29 \\
& & b & \end{array}$ & $12{\frac{19}{i^{\prime}}}^{11}$ & $\frac{13}{j^{\prime}}$ & 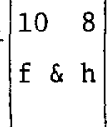 & $\mid \begin{array}{cccc}23 & 25 & 22 & 20 \\
\text { e } & \& & g\end{array}$ & $\begin{array}{ll}2 & 1 \\
1 & \end{array}$ & $\begin{array}{lll}7 & 6 & 5 \\
k^{\prime} & \end{array}$ & $\begin{array}{l}18 \\
\mathrm{~m}\end{array}$ \\
\hline $\begin{array}{l}\text { Canopy } \\
\text { type }\end{array}$ & & Oak & $\begin{array}{c}\text { Oak } \\
\text { Pine } \\
\text { Pine/Oak }\end{array}$ & $\begin{array}{l}\text { Pine } \\
\text { Spruce }\end{array}$ & Pine & Mixed & Mixed & Mixed & $\begin{array}{l}\text { Pine } \\
\text { Spruce }\end{array}$ & $\begin{array}{l}\text { Pine } \\
\text { Spruce }\end{array}$ & $\begin{array}{l}\text { Maple } \\
\text { (Pine) }\end{array}$ \\
\hline Group & & & $A^{\prime}$ & & $B^{\prime}$ & & $\mathrm{C}^{\prime}$ & & & ' & $\mathrm{E}$ \\
\hline
\end{tabular}

The underlined numbers indicate releves which changed sub-group affinity from the 4-strata analysis to the 3-strata analysis.

species present in both relevés. For two sets with $A$ and $B$ representing the species present in each of two relevés, $D I F 1$ is calculated:

$$
D I F 1=(A \triangle B) / A \cup B
$$

where the operator $\mathrm{F}$ is an exclusive 'or' and the operator $U$ signifies union. Consequently, $D I F 1$ is the one-complement of the Jaccard similarity index. $D I F 1$ does not use the cover/abundance values of the releve data. Consequently, this measure distinguishes only those relevés that differ in species composition; it does not segregate releves on the basis of different cover values of species in common.

Difference $D I F 2$ is designed to incorporate presence/ absence and cover/abundance data into the inter-plot difference values. For two plots with a total of $i$ species, the relation is:

$$
\text { DIF } 2=\frac{\sum_{i=1}^{M}\left|A_{i}-B_{i}\right|}{\sum_{i=1}^{M}\left(A_{i}+B_{i}\right)}
$$

where $A_{i}$ is the cover/abundance value for the $i$ th species in plot $A$ and $M$ is the total number of species in the sample. DIF 2 is a variation of the Czekanowski (1909, 1932) index. In $D I F 2$ the difference values always range between 0 and 1 for any two plots while the difference values for the Czekanowski index can be any positive number.

Both $D I F 1$ and $D I F 2$ supply difference values between every pair of plots. These difference values can be generated by analyzing any stratum individually or by analyzing any 
combination of strata simultaneously. When two or more strata are analyzed, only the species present in these strata are considered. If a species is present in two or more strata, the highest cover/abundance value is used in the calculation of $D I F$ 2. All difference values between plots, regardless of the number of strata in the analyses, range between 0 and 1 . A difference value of 0 means that two plots have exactly the same species and, in the case of $D I F 2$, they have exactly the same cover/abundance values as well. A difference value of 1 means that the two have no species in common.

After the appropriate distance values are calculated, the relevés are clustered into hierarchical groups by the 'farthest neighbor' (also known as the complete linkage) combinatorial method of Lance \& Williams (1967). Sneath \& Sokal (1973) have presented a critical discussion of this and related agglomerative procedures. Other combinatorial methods including the nearest neighbor (single linkage) and weighted mean were tried but rejected because of their effects on the distance between groups of relevés. The farthest neighbor method was chosen because it dilates the distance between groups of relevés. Dilating the distance is desirable with the data because: (1) the subgroups that arose naturally in the agglomeration were more clearly displayed, ..nd (2) the groups aggregated around species significant to the structure of the community. Even though sample locations were chosen carefully within each plantation, all effect of the edges, foot-

Table 3. Arrangement of relevés into groups and sub-groups relating to tree canopy cover types by $D I F 2$, based on cover/ abundance data for species. 3a: the arrangement achieved by RUN 1 using data from all four strata. 3b: the arrangement achieved by RUN 2 using data only from the lower three strata. Little change in the groups and sub-groups takes place when the tree canopy stratum is omitted from the calculations, indicating consistency or coherence between the tree canopy and the understory strata when analyzed for cover/abundance.

Table $3 a$

DIF 24 STRATA FARTHEST NEIGHBOR

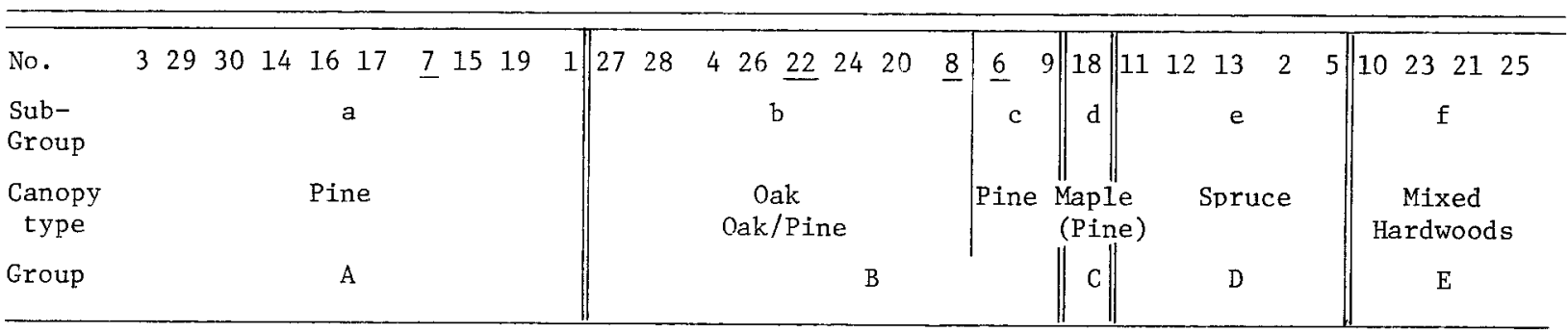

Table $3 b$

DIF 2 BOTTOM 3 STRATA FARTHEST NEIGHBOR

\begin{tabular}{|c|c|c|c|c|c|c|c|c|c|c|c|}
\hline $\begin{array}{l}\text { No. } \\
\text { Sub- } \\
\text { Group }\end{array}$ & $14 \quad 16 \quad 22 \quad 15$ & $\begin{array}{crrrr}17 & 3 & 29 & 19 & 30 \\
a^{\prime} & & & & \end{array}$ & 1 & $\begin{array}{r}18 \\
\mathrm{~d}\end{array}$ & \begin{tabular}{|rr|ll}
8 & 9 & 27 & 28 \\
& $c^{\prime}$ & &
\end{tabular} & $\begin{array}{cccc}4 & 26 & 20 & 24 \\
b^{\prime} & & & \end{array}$ & $\begin{array}{cccc}10 & 23 & 21 & 25 \\
& \mathrm{f} & \end{array}$ & 5 & $\underline{6}$ & $\begin{array}{c}7111213 \\
\mathrm{e}^{\prime}\end{array}$ & 2 \\
\hline $\begin{array}{l}\text { Canopy } \\
\text { type }\end{array}$ & & $\begin{array}{c}\text { Pine } \\
\text { Pine/Oak }\end{array}$ & & Maple & e) Pine & Oak & $\begin{array}{c}\text { Mixed } \\
\text { Hardwoods }\end{array}$ & & & $\begin{array}{l}\text { Spruce } \\
\text { (Pine) }\end{array}$ & \\
\hline Group & & $A^{\prime}$ & & $\mathrm{C}$ & $B^{\prime}$ & & $\mathrm{E}$ & & & $D^{\prime}$ & \\
\hline
\end{tabular}

The underlined numbers indicate relevés which changed sub-group affinity from the 4-strata analysis to the 3-strata analysis. 
paths, and cuttings could not be avoided. But by employing a space dilating technique, relevés sharing characteristic disturbance species with a member of a given group were prevented from joining. The other combinatorial methods, which are not space dilating, often clustered relevés on the basis of disturbance species.

Both DIF 1 and DIF 2 were employed twice in the analyses. Run 1 of $D I F 1$ and run 1 of DIF 2 used the relevés from all 30 plots and all four strata. In run 2 of $D I F 1$ and run 2 of $D I F 2$, the canopy data were omitted from the analysis. All four sets of difference values were subsequently analysed by the farthest neighbor method and phenograms were generated (figures 2-5).

\section{Results and discussion}

Saginaw Forest is composed of small stands of native and exotic species of canopy trees; the exotic species, the mixtures of exotic and native species, and even the native species in pure, evenly spaced stands provide canopies that would not occur naturally. This property provides a special opportunity to study the effects of the canopy on the structure and composition of the understory because such factors as macroclimate, vector availability, dispersal agents, soils, and topography differ relatively little between plots.

In the DIF 1 analyses, small, relatively stable subgroups are formed (Figs. 2, 3, tables 2a, b) ; however, the relationships among them change from run 1 to run 2 when the canopy species are removed. While the subgroups themselves represent floristically similar clusters of relevés, the larger groups (separated by double lines in Tables $2 \mathrm{a}, \mathrm{b}$ ) that are formed are uninterpretable phytosociologically. The total rearrangement of subgroups between the two RUNs suggests that presence/absence data alone do not sufficiently show the relationships (if any exist) between groups of plots.

The DIF 2 analyses (Figs. 4, 5, Tables 3a, b) reveal the advantages of incorporating the relevé cover/abundance values. Although the canopy species are much more heavily weighted in DIF 2 (DIF 1 weighs a solid Quercus canopy and a single rare herb equally), their removal in run 2 causes little rearrangement of the releves. Large stable groups of plots are maintained from run 1 to run 2 . These groups are composed of relevés which have similar or identical canopies. The DIF 2 analysis, therefore, indicates that the understory development is not unpatterned. Similar canopies have similar understories.
However, the differences between the groups of relevés are not due, in a large part, to different species compositions in the understory, but to different relative abundance values for species.

It is not surprising that the DIF 1 analyses are inconclusive. Because Saginaw Forest is small, most of the species present have had ample opportunity to disperse throughout the forest area. The various forms of disturbance, such as foot paths, stand thinning, and edge effect, would tend to favor the propagation of certain species throughout the forest. Also, there is probably some mixing of the litter that creates islands of favorable sites in otherwise inhospitable plantations. These phenomena would tend to equalize the species composition of all the plots without markedly altering relative abundances.

Many environmental factors are acting in the determination of the structure of the understory in each plot. Among these are certainly water and light availability, soil type and nutrient content, allelochemic interactions, microtopography, and animal predation (Moir 1966, Anderson et al. 1969, Rice 1974, Christensen \& Muller 1975, Lodhi 1976, Bratton 1976). This study does not undertake to determine the actual pathways of the influence of the canopy on the understory, but only to note their effects as shown by changes in species composition.

The complete matrix of relevés (Table 1) has the columns ordered in keeping with Table $3 \mathrm{a}$ ( $D I F 2$, bottom 3 strata), and the rows of species are generally in the sequence of canopy tree species occupying the canopy layer (stratum 1) or occurring in four layers, shrub and tree species occurring in strata 2 to 4 , and herbaceous species in stratum 4 . Mosses and lichens were not included in the relevés.

Numerical methods for analyzing phytosociological data matrices have appeared with increasing frequency in the past decade (see review by van der Maarel 1974, and Westhoff \& van der Maarel 1978) but as far as we know, none of the published methods is capable of analysing strata or examining the influence of the canopy composition on understory vegetation.

\section{Summary}

During May and June, 1974, relevés were obtained from 30 plantation stands in the Saginaw Forest in southeastern Michigan. The canopy trees in these plantations were planted between 1904 and 1938. The understory has developed naturally over the years. The forest plantations offer opportunities for study of the effects of the canopy 
on the structure and species composition of the understory.

A new numerical method of data structuring was used, which is based on the detection patterns of associated species within the table of 30 relevés from Saginaw Forest plantations. The method employs two difference measures. DIF 1 uses presence/absence data and DIF 2 the cover/ abundance values obtained from the relevés. Both difference measures supply distance values for every pair of relevés. The least dissimilar relevés are then grouped together by the farthest neighbor agglomerative algorithm of Lance \& Williams (1967).

The DIF 1 analysis was inconclusive, but the DIF 2 analysis gave coherent results. It has shown that relevés with similar canopies have similar understories. The differences in understories among the relevés are due less to species composition than to the relative abundances of the species.

\section{References}

Anderson, R.C., Loucks, O.L., \& A.M. Swain. 1969. Herbaceous response to canopy cover, light intensity, and throughfall precipitation in coniferous forests. Ecology 50: 255-263.

Benninghoff, W.S. 1966. The relevé method for describing vegetation. Michigan Bot. 5: 109-114.

Bratton, S.P. 1976. Resource division in an understory herb community: responses to temporal and microtopographical gradients. Amer. Nat. 110: 679-693.

Braun-Blanquet, J. 1932. Plant Sociology: the study of plant communities (English translation by G.D. Fuller \& H.S. Conard). McGraw-Hill Book Co., New York, 439 pp.

Braun-Blanquet, J. 1964. Pflanzensoziologie. 3rd ed. SpringerVerlag, Vienna and New York, $865 \mathrm{pp}$.

Christensen, N.L. \& C.H. Muller. 1975. Relative importance of the factors controlling germination and seedling survival in Adenostoma chaparral. Amer. Midl. Nat. 93: 71-78.

Czekanowski, J. 1909. Zur Differentialdiagnose der Neandertalgruppe. Korrespondenzblatt Deutsch. Ges. Anthropol. Urgesch, 40: 44-47.

Czekanowski, J. 1932. 'Coefficient of racial likeness' und 'durchschnittliche 'Differenz.' Anthrop. Anz. 9: 227-249.

Gleason, H.A. \& A. Cronquist. 1963. Manual of Vascular Plants of Northeastern United States and Adjacent Canada. D. Van Nostrand Company, Inc. Princeton, New Jersey, 810 pp.

Lance, G.N. \& W.T. Williams. 1967. A general theory of classificatory sorting strategies. I. Hierarchical systems. Computer J. 1: 15-20.

Lodhi, M.A.K. 1976. Role of allelopathy as expressed by dominating trees in a lowland forest in controlling the productivity and pattern of herbaceous growth. Amer. Jour. Bot. 63: 1-8;

Maarel, E. van der. 1974. The Working Group for Data-Processing of the International Society for Plant Geography and Ecology in 1972-1973. Vegetatio 29: 63-67.
Moir, W.H. 1966. Influence of ponderosa pine on herbaceous vegetation. Ecology 47: 1045-1048.

Rice, E.L. 1974. Allelopathy. Academic Press, New York. $353 \mathrm{pp}$

School of Natural Resources, University of Michigan. 1966. A guide to Saginaw Forest. Ann Arbor, Michigan, 60 pp. mimeographed.

Sneath, P.H.A. \& R.R. Sokal. 1973. Numerical Taxonomy. W.H. Freeman \& Co., San Francisco, 573 pp.

Westhoff, V. \& E. van der Maarel 1978. The Braun-Blanquet approach. 2nd. ed. In: R.H. Whittaker (ed.) Classification of plant communities, p. 287-399. Junk, The Hague.

Accepted 15 July 1979 